\title{
Doctoral Theses from Nursing Postgraduate Programs in Brazil and their Association with the Millennium Development Goals
}

\author{
Rosalina Aparecida Partezani Rodrigues ${ }^{1}$ \\ Maria Lúcia do Carmo Cruz Robazzi ${ }^{1}$ \\ Alacoque Lorenzini Erdmann² \\ Josicélia Dumet Fernandes ${ }^{3}$ \\ Alba Lucia Bottura Leite de Barros ${ }^{4}$ \\ Flávia Regina Souza Ramos²
}

Objectives: The Millennium Development Goals are centered around combatting poverty and other social evils all over the world. Thus, this study seeks to identify the Millennium Development Goals as an object of study in theses from Postgraduate Nursing Programs in Brazil scoring 5 (national excellence) and 6 or 7 (international excellence), and evaluate the association between the score for the program and achieving the Millennium Development Goals. Method: Exploratory descriptive document research. Data were collected from the Notes on Indicators/Coordination for Higher Education Personnel Improvement for the 15 Postgraduate Nursing Courses scoring between 5 and 7 in the three-year-period of 2010/2012. Results: of the 8 Millennium Development Objectives, 6 were dealt with in the theses. There was an association (Fisher's exact test $\mathrm{p}$-value $=0.0059$ ) between the distribution of the theses and the program scores in relation to the Millennium Development Objectives ( $p$-valor $=0.0347$ ) Conclusion: the doctoral theses were slightly related to the Millennium Development Objectives, covering the population's economic development, health conditions and quality of life. It is recommended that Postgraduate Programs in Nursing pay closer attention to the Millennium Development Objectives..

Descriptors: Nursing; Millennium Development Goals; Education, Nursing, Graduate.

\footnotetext{
${ }^{1}$ PhD, Full Professor, Escola de Enfermagem de Ribeirão Preto, Universidade de São Paulo, PAHO/WHO Collaborating Centre for Nursing Research Development, Ribeirão Preto, SP, Brazil.

2 PhD, Full Professor, Universidade Federal de Santa Catarina, Florianópolis, SC, Brazil.

3 PhD, Full Professor, Universidade Federal da Bahia, Salvador, BA, Brazil.

${ }^{4}$ PhD, Full Professor, Universidade Federal de São Paulo, São Paulo, SP, Brazil.
}

Corresponding Author:

Rosalina Aparecida Partezani Rodrigues

Universidade de São Paulo. Escola de Enfermagem de Ribeirão Preto

Departamento de Enfermagem Geral e Especializada

Av. Bandeirantes, 3900

Bairro: Monte Alegre

CEP: 14040-902, Ribeirão Preto, SP, Brasil

E-mail: rosali
Copyright (c) 2015 Revista Latino-Americana de Enfermagem This is an Open Access article distributed under the terms of the Creative Commons Attribution Non-Commercial License (CC BY-NC).

This license lets others distribute, remix, tweak, and build upon your work non-commercially, and although their new works must also acknowledge you and be non-commercial, they don't have to license their derivative works on the same terms. 


\section{Introduction}

The mission of the United Nations Development Program (UNPD), established by the United Nations (UN) is to collaborate in development and eliminate poverty, as well as contributing to achieving the Millennium Development Goals (MDG)(1). These objectives aim to improve the destiny of humanity in this century and involve the areas of social public policy and commitment to development on all continents( ${ }^{(1)}$.

In 2000, though the UNPD, Brazil and another 188 nations signed up to an agreement to combat extreme poverty and other evils of world society. This commitment was explained using the eight MDGs to be attained by 2015. Part of the United Nations Millennium Declaration, the goals are a series of commitments aiming to improve the fate of humanity in this century. There are 8 goals, namely: 1) reduce poverty/hunger/ misery by half; 2) achieve universal access to primary education; 3) promote gender equality; 4) reduce infant mortality; 5) improve maternal health; 6) combat HIV/ AIDS, malaria and other diseases; 7) quality of life and guaranteed environmental sustainability and 8) establishing development partnerships ${ }^{(1)}$.

Brazil and the other countries have been seeking to achieve these objectives, fulfilling their commitment.

The place of universities in this search stands out, as they are a space in which excellence in higher education is promoted, in which young citizens committed to ethics, to social responsibility and to sustainable development are trained, in which teaching, research and extension are developed, in which technological advances are made, and knowledge and techniques socially necessary for developing human well-being are produced/ disseminated, as are economic and social policies, as well as being a place in which science is generated ${ }^{(2-6)}$, among other things.

University, then, is an instrument for social change and it is assumed that Postgraduate Programs, especially those with international impact and gaining the highest scores, should meet the demands of research and training researchers committed to making the advances necessary to society. It is expected that these Postgraduate Programs are committed to the UN UNPD, producing knowledge that can have an impact on achieving the MDGs, showing their social relevance.

Within the university, the Area of Nursing is a science which views the person (individuals, families, communities), the environment and health as central, at any point of the lifecycle, when one falls ill, the severity and conditions ${ }^{(7)}$. Nursing seeks to provide the individual with comprehensive care, conducting interventions dependent on or independently of other health care professionals and team members, producing knowledge about care processes, managing the care environment and the nursing professionals involved there, as well as public management.

The issues raised in national and international agreements can be viewed as tools for analyzing the knowledge produced in this area. Thus, the 24 Ministry of Health priority agendas and the MDGs, with their 22 aims and 48 indicators for global development can be used as tools for reflection, so long as they are not viewed as linear, mandatory demands, decontextualized from the Brazilian reality of the specific field of nursing.

The policy of investing in studies with lines of research aiming at reducing social inequality and promoting social inclusion has received attention in Nursing Postgraduate Programs (PGPNur)

This is the perspective used in this study, recognizing the MDGs as important international guidelines for the field of health care, considering the strategic role of the University and of Postgraduation, as well as bearing in mind that the area of Nursing should value multiple references, beyond the theoretical and policy frameworks when planning interventions and commitment to producing knowledge.

In the Brazilian Postgraduate system, programs are generally evaluated by the Coordination for Higher Education Personnel Improvement - Coordenação de Aperfeiçoamento de Pessoal de Nível Superior (CAPES), receiving scores that range from 3 to 7 , with those scoring 3 to 4 meeting national requisites, but excluding internationalization.

In the Area of Nursing, Programs scoring 5 (national excellence), 6 and 7 (international excellence) are those that receive the highest scores and meet the CAPES indicators and criteria, of which some categories stand out, namely: Solidarity, Nucleation, Leadership and Internationalization. Solidarity refers to cooperation with other programs, working as part of a network, advisory services for formulating proposals for new national or international courses, participating in joint projects with as yet unconsolidated research groups, among other indicators. Nucleation indicates the capacity of the program to train postgraduates and turn them into educators, researchers and leaders in health care, specifically in nursing. Leadership is represented by the draw of students and lecturers, of different regions of the country and abroad for doctoral 
and $\mathrm{PhD}$ internships. Internationalization refers to student and lecturer participation in international exchange programs, organizing international events, establishing cooperation agreements, as well as producing international scientific output of national impact on public policy, among others ${ }^{(10)}$.

For this set of categories, the PGPNur scoring 5, 6 and 7 for CAPES should be guided along two principals, namely, knowledge and research and teaching, allowing knowledge exchange between researchers, lecturers and students, whose academic activity should be linked to concrete social problems and needs, such as health, education, violence, human rights or the environment, among others.

It is likewise the responsibility of these programs to consider the contribution of nursing in achieving the MDGs in Brazil, with a critical. In-depth awareness of the discourse and goals proposed in the broader agendas and global documents.

In light of such considerations, the need arises for this study, which takes the following question as its starting point: are the MDGs an object of study in theses from Brazilian Postgraduate Programs in Nursing scoring 5,6 , and 7 ?

The hypothesis established was that there was an association between the distribution of theses produced from the Nursing Programs evaluated with the highest CAPES scores and their relationship with the MDGs.

The aim of this study, then, is to identify the presence of the MDGs as an object of study in theses produced by PGPNur with scores of 5 (national excellence), 6 and 7 (international excellence) in Brazil and evaluate the association between the program score and whether or not the MDHs are covered.

As of this moment, there are no similar studies in the literature examined. It is hoped that this study may contribute to guiding the health care area, specifically that of nursing in Brazil, in the future.

\section{Method}

This was a descriptive, exploratory documentary study. Between September and October 2014, data were taken from the CAPES Notes on Indicators for Postgraduate Programs in Nursing for Doctorate courses awarded scores of 5 to 7 by the Nursing Evaluation Commission. (11) The data referred to the 2010-2012 period.

These programs were selected due to their better performance in the regular CAPES evaluations, with consolidated national and international positions and robust scientific output, as well as meeting the requirements for solidarity, nucleation and leadership described above(10).

Firstly, all of the stricto sensu Nursing Postgraduate Programs were accessed on the CAPES site. Of the 28 PGPNur, 15 scored between 5 and 7, above the average; and these included those deemed excellent (scores of 6 or 7), for their international consolidation and visibility. Doctoral theses defended were examined for the above mentioned three-yearperiod in the 15 programs identified (scores of 5-7) and titles were obtained.

After obtaining the titles, the abstracts of these theses were sought in the online thesis and dissertation archives at the universities which delivered the PGPNur as well as the CAPES online thesis library.

A printed record was used to collect the data, including the following information: name of the program, institution to which it belongs, titles and abstract of the theses defended in the period in question.

We identified 15 PGPNur with scores of 5,6 and 7 , of which ten scored 5 and five scored 6 or 7 . The Programs were allocated a number $(1,2,3 \ldots)$ to preserve the anonymity required for such a study.

Information was inputted into two spreadsheets, the first containing the titles and abstracts of the theses and the second the eight MDGS. The titles and abstracts were used to identify the object of study of the theses. Next, any correspondence of the object of study with the MDGs was identified.

The objects of study were classified/categorized according to the MDGs recorded in the second spreadsheet. The theses whose objects of study did not explicitly include the MDGs were denominated "No MDG identified".

Corresponding the thesis to the MDS was done by each of this study's authors first individually, and later in a group, until concordance was reached concerning the categorization of each doctoral theses' object of study's correspondence to the eight MDGs. Theses whose abstracts and titles fitted into more than one of the MDGs were classified in only one of them.

The data were transferred onto an Exce spreadsheet and then underwent descriptive analysis and interpretation in light of the selected literature, aiming to achieve the proposed objective. Fisher's exact test was used to analyze whether or not the theses studied covered an MDG and the level of significance was $5 \%(0,05)$. 
This study was not submitted to the Research Ethics Committee, as the data analyzed are available on the official CAPES site ${ }^{(11)}$ and in the online libraries of the Universities and are thus considered information in the public domain, the participants in the study are not identified and there is no direct involvement of human beings as research subjects, following National Health Council recommendations and those of the Universities from whence came the theses analyzed.

\section{Results}

The analysis identified a total of 15 PGPNur, of which $66.6 \%$ scored $5,20 \%$ scored 6 and $13 \%$ scored 7 . These Programs were located in the Northeast $(6.6 \%)$, Southeast $(80 \%)$ and South $(13.3 \%)$ of Brazil. Of the 477 theses produced in these Programs in the period studied, 272 (57.02\%) were defended in Programs scoring 5, $129(27.04 \%)$ in those scoring 6 and 76 $(15.93 \%)$ in those scoring 7 . These data are shown in Table 1 below.

Table 1 - Distribution of the doctoral theses according to year and the respective scores of the Postgraduate Programs in Nursing. Ribeirão Preto, SP, Brazil, 2014

\begin{tabular}{lcccc}
\hline Scores/year & $\mathbf{2 0 1 0}$ & $\mathbf{2 0 1 1}$ & $\mathbf{2 0 1 2}$ & Total \\
\hline 5 & 70 & 94 & 108 & 272 \\
6 & 40 & 42 & 37 & 129 \\
7 & 18 & 27 & 31 & 76 \\
Total & 128 & 163 & 176 & 477 \\
\hline
\end{tabular}

Source: www.capes.gov.br

Data showing the theses' inclusion of the MDGs are shown in Table 2.

When Fisher's exact test was applied to the data in Table 2 the result was $p$-value $=0.0059$, in other words, lower than 0.05 , confirming the hypothesis that there is a link between the distribution of the theses produced in the Nursing Programs awarded the highest CAPES scores and their link with the MDGs.

The lack of studies explicitly identified as adhering to MDG 1 (reducing poverty/hunger/misery) by half) and 2 (universal access to primary education) does not mean lack of interest in these topics as there are studies which, indirectly, approach not only the link between economic development and health conditions and quality of life in the population, but also the contribution to universal access to primary education and reducing poverty/hunger/misery.

Although MDG number 8 (establishing partnerships for development), 3 (promoting gender equality), 4 (reducing infant mortality) and 7 (quality of life and guaranteed environmental sustainability) are covered in the theses analyzed, they still lack greater investment, considering their importance in improving the quality of life and health of the population.

The inclusion of MDGs 5 (improving maternal health) and 6 (combating HIV/AIDS, malaria and other diseases) in the theses is shown through studies of professional practice in the areas of women's health, children's health and adult health, with emphasis on public health care and understanding the multiple aspects involved in nursing care. These studies, which cover the MDGs, reflect the presence of research into chronic illness and complications related to aging and chronicity, as well epidemiological and demographic changes to the profile of the population.

The theses which were not identified as associated with the MDGs, 303 of 477 , equal to $63.52 \%$ and include studies which demonstrate Nursing practice in diverse contexts and with different populations. To the authors if this study, it appears that the researcher opted to conduct research according to their vocation as researcher and to the line of research of each PGPNur. These theses included studies related to health in workers and in the elderly, topics relevant to current society, as the demographic transition in the country is gathering pace and working life has changed in recent years. Other research also attracted attention, such as use of language system and humanized care at different stages of the life cycle. Methodological concerns were also shown to be objects adding value to research in the area and advancing the process of constructing knowledge. Table 3 shows the presence of the theses in the PNPNur with scores of 5,6 and the MDGs, as well as the p-value found.

Given the results shown in Table 3 and the $p$-value of 0.0347 found using Fisher's exact test, the hypothesis is confirmed that there is an association between scores of 5, 6 or 7 for the PGPNur and the distribution of doctoral theses and presence or not of the MDG as objects of study in the theses evaluated.

It was shown, then, that the Fisher's exact test $(p$-value $=0.0059)$ confirmed the hypothesis that there is an association between the distribution of theses produced by the PGPNur according to their scores and the MDGs included in them, as well as the p-value 0.0347 which also showed that there was an association between the scores for these Programs and the distribution of the theses and covering the MDGs or otherwise.

Some 174 (36.48\%) of the doctoral theses analyzed covered the MDGs. Of these, $63(36.21 \%)$ covered MDG 
6 (combating HIV/AIDS, malaria and other diseases); 43 (24.71\%) covered MDG 5 (improving maternal health) and $30(17.24 \%)$ included MDG 4 (reducing infant mortality).
On the other hand, no studies were found with objectives compatible with MDG 1 (reducing poverty/hunger/misery by half) or 2 (universal access to primary education).

Table 2 - Distribution of doctoral theses produced in Nursing programs scoring 5, 6 and 7 and their relationship with the Millennium Development Goals 2010/2012. Ribeirão Preto, SP, Brazil, 2014

\begin{tabular}{|c|c|c|c|c|c|c|}
\hline \multirow{2}{*}{ MDG } & \multicolumn{4}{|c|}{ Scores } & \multirow{2}{*}{ Total } & \multirow{2}{*}{$\%$} \\
\hline & $6 / 7$ & $\%$ & 5 & $\%$ & & \\
\hline 1. Reducing poverty/hunger/misery by half & - & - & - & - & - & \\
\hline 2. Universal access to primary education & - & - & - & - & - & \\
\hline 3. Promoting gender equality & 4 & 80.0 & 1 & 20.0 & 5 & \\
\hline 4. Reducing infant mortality & 11 & 36.6 & 19 & 63.4 & 30 & \\
\hline 5. Improving maternal health & 18 & 41.8 & 25 & 58.2 & 43 & \\
\hline 6. Combating HIVIAIDS, malaria and others & 37 & 58.7 & 26 & 41.3 & 63 & \\
\hline 7. Quality of life and guaranteeing environmental sustainability & 14 & 63.6 & 8 & 36.4 & 22 & \\
\hline 8. Establishing partnerships for development & 2 & 18.2 & 9 & 81.8 & 11 & \\
\hline 9. No MDG identified & 119 & 39.2 & 184 & 60.7 & 303 & \\
\hline Total & 205 & & 272 & & 477 & 100 \\
\hline
\end{tabular}

Source: www.capes.gov.br

Table 3 - Distribution of doctoral theses and presence, or otherwise, of Millenium Development Goals, according to Postgraduate Programs in Nursing awarded scores of 5, 6 and 7. Ribeirão Preto, SP, Brazil, 2014

\begin{tabular}{lcccc}
\hline MDG* $^{*}$ & Score 6/7 & Score 5 & Total & p-value \\
\hline Yes & 86 & 88 & 174 & 0,0347 \\
No & 119 & 184 & 303 & \\
Total & 205 & 272 & 477 & \\
\hline
\end{tabular}

*MDG: Millennium Development Goals

Source: www.capes.gov.br

\section{Discussion}

In the context of the domains, properties, coverage and depth of scientific knowledge produced, expected of the output of doctoral training and advanced research, it is complicated to make comparisons or judgements on their importance and relevance when the focus is on meeting or following one or more of the 8 MDGs. These MDGs a priori are not presented in order of importance of priority, nor do they represent the specific needs of each and every nation or country but are all, in some way, important and necessary for improving the health of humanity in this century. They represent a set of needs to guide the efforts of all nations, within or beyond their own borders.

Brazil is a large and complex country which has undergone rapid economic, social and environmental change. There have been significant advances in health status and life expectancy recorded (12). In spite of this, regional differences remain in terms of economic and social development, impacting on the education and health of the population. Some of these impacts are tangential to the MDGs. It should be pointed out that human resources in health care remain insufficient. The Ministries of Health and Education are investing heavily in Undergraduate Programs in nursing and dentistry, with the focus on primary care. This focus is in line with the proposed national Health Care System, The Unified Health Care System (SUS)(12).

The PGPNur respond to this trend, seeking the answers to social issues relevant to this country, as already mentioned. Results presented at the most recent Brazilian Nursing Congress (CEBEN show that, in relation to the tree of knowledge proposed by the National Council for Technological and Scientific Development - Conselho Nacional de Desenvolvimento Tecnológico e Científico (CNPq) and coordinators of the Postgraduate programs to substitute the current one (13), the greatest demand for resources is in the area of Public Health (30\%), followed by Adult and Elderly Nursing (22\%)and Nursing in Child and Adolescent Care (16\%). Resources are being directed to the different calls from this research agency. As for research priorities on the national agenda, those with the 
greatest demand are non communicable diseases, health in the workplace and biosecurity ${ }^{(14)}$.

As Nursing is a field of knowledge in health care, it is both important and necessary to recognize and value the discipline and its particular knowledge, its interface and coverage of domains including health care science and other parallel and complementary disciplines and partnerships with common foundations. Moreover, training doctorates with greater dominion of basic and clinical and translational research and other advances in the process of constructing inter-disciplinary knowledge should result in greater contributions to solving health care problems and the socio-political implications of promoting health and better quality of life for the citizens ${ }^{(15)}$

This adherence to objects and foci of intervention in the field of health may explain the lack of or small number of theses related to MDGs 1,2 and 8 . These are goals whose contents are of a basically intersectoral and economic nature, such as reducing poverty/hunger/ misery and establishing partnerships for development, or else traditionally linked to the field of education, such as universal access to primary education. There is no denying the link between economic development and any analysis of health conditions, but this was not deemed a priority object of research in nursing. Development, the economy and primary education are rather contextual elements, or those which interface with the most varied objects of study in Nursing.

Another MDG with which few doctoral theses were linked was number 3 (promoting gender equality) which, although not restricted to the field of health care, is obviously related. Thus, topics such as violence against women, sexuality and specific social vulnerability were the object of five (5) theses which, with different focuses, seem to contribute to promoting health with greater gender equality.

MDGs 4 and 7 were slightly better represented, although with a low number of doctoral theses, 30 and 22, respectively. The former, reducing infant mortality, may perhaps be attributed to a long history of public policies of investment in this focus. Thus, mortality of under $5 \mathrm{~s}$ in Brazil declined by $4.8 \%$ per year since 1990 , when the requirement was a $4.2 \%$ drop, meaning that by 2011 this objective was on the way to being met (12). The latter, quality of life and guaranteed environmental sustainability, has increased in prominence over the last two decades and still requires intense investment. The doctoral theses in Nursing approach this in a more particular was, quality of life from the point of view of specific populations, such as the elderly, children, adolescents or those with specific, especially chronic, health problems.

The existence of theses in the three years studies which focus on the issue of the environment, reflect the interface between health and the environment as an important demand for health promotion and education actions, as well as the need to encourage development of responsible actions minimizing environmental impact in different contexts, from education in communities ${ }^{(16-17)}$ to hospital work(18).

MDG 5, improving maternal health, was in greater evidence with 43 doctoral theses identified, exploring traditional topics of professional practice linked to maternity (antenatal, birth, postpartum, breastfeeding), to public health problems, such as prevention, follow up and care for women with breast and cervical cancer and abortion; through foci constructed on a clinical or epidemiological approach, or even an approach covering the multiple aspects involved in nursing care.

MDG 6, combatting HIV/AIDS, malaria and other diseases, was the goal linked with the highest number of theses, a total of 63 . However, one must take into account the small number of studies on HIV/AIDS and that none were on malaria. Most of the doctoral theses evaluated referred to "other diseases", which covers those of epidemiological importance in Brazil, such as tuberculosis, leprosy, schistosomiasis and sexually transmitted diseases, as well as chronic diseases such as diabetes mellitus, arterial hypertension, heart disease and others such as Alzheimer's, Parkinson's, mental illness and problems linked to drug addiction and mental health.

Although the MDG does not list which other diseases are included, when the aims to be achieved are explained, tuberculosis and leprosy are mentioned, as well as HIV/AIDS and malaria. It is therefore important to analyze this strong interest in topics related to chronic illness, recognizing the trends for changes in the epidemiological and demographic profile of the Brazilian population which indicate the great importance of health problems related to ageing and chronicity.

Health policy innovations in Brazil and their impact on health conditions indicate that HIV prevalence has remained stable since 2000; some diseases, 
preventable through vaccination (polio, measles and diphtheria), were almost completely eradicated, as were diarrhea and Chagas disease. Simultaneously, on the topic of infectious diseases, there was partial success in controlling hepatitis $A$ and $B$, tuberculosis and malaria and failure to control dengue or visceral leishmaniasis ${ }^{(12)}$. Thus, the concern of Brazilian nurses with diseases such as tuberculosis is consistent, and it is also worth pointing out the lack of studies on malaria. Perhaps given the concentration of cases in the Amazon region, which is just where there is the greatest lack of research in Nursing and no PGPNur. However, this reasoning is not applicable to leishmaniasis and dengue, which affect almost all the states of Brazil.

The objects of study of the 63 doctoral theses, in terms of what is covered by this broad spectrum (other diseases), includes a variety of theoreticalmethodological approaches, target population or way of approaching the "diseases", mainly for the concern with analyzing the relation of clinical and cultural knowledge with the intervention and the role of nursing in individual and collective health care practice.

This analysis corroborates the social need for research conducted in the Postgraduate Programs, considering the complexity of health care and of the systems responsible for providing qualified services and actions, for promoting health and preventing and treating disease. Moreover, research in Nursing is essential in order to preserve, promote and renew the scientific basis of the discipline, in the face of social dynamism (19).

Finally, on the majority of the doctoral theses (303 of 477 , or $63.52 \%$ ) in which no clear evidence was identified of a link with any of the MDGs, we have to bear in mind that this lack of link does not mean that the issues researched are not relevantly formulated, or not in adherence to problems in the real context of the life and health of Brazilians, but only that the MDGs cannot be applied, linearly, to any context and may indicate, or not, priorities for each country. By signing up for the MDGs, Brazil reaffirmed its commitment to contributing to achieving them on a global scale, even if some of them were not the focus of priority intervention.

From another point of view, it falls to each profession, especially in the health care field, to reflect on the compatibility, or otherwise, of its objectives and lines of research with the MDGs, because, as has been stated above, not all are located, strictly speaking, in this field. It is essential to recognize that Nursing will always be exclusively responsible for conducting studied on objectives inherent to itself, capable of broadening the body of knowledge and capacity to respond to old and new questions raised by the work. In other words, the theses which were not explicitly linked to the MDGs are focused on content which is important for advances in the science/discipline of Nursing, by exploring care technologies in Nursing, knowledge and professional practice, working conditions, care and service organization, the problem solving potential of the specific or multi-professional work and of the experiences of the subjects who are the object of their professional activity, among many other topics.

The PGPNur are guided by academic teaching, research and extension activities linked to the concrete social problems and wants, although terminology is still weakly directly linked to those of the MDGs. This does not mean, however, that these studies are not linked to actions that seek to reduce social inequality and promote social inclusion. On the contrary, they are studies seeking to improve the fate of humanity, through contributing to solving health problems and the socio-political implications of promoting health and better quality of life for citizens.

The policies used to evaluate Postgraduate Programs in this country, established by the Ministry of Education Coordination for Higher Education Personnel Improvement, encourage social, political and technological responsibility in training human resources with excellence. Moreover, advances in the area of Nursing have been marked by reducing regional inequalities in the distribution of courses in almost all regions of the country, as well as by their better qualification $^{(10)}$.

The limits to initially becoming closer should also be recognized, as permitted by analyzing the theses based on their titles and abstracts and in the relatively recent timeframe used (the last 3 years), which did not allow light to be shed on important points of reflection on the trends and perspectives of lines of research and research priorities in Nursing in Brazil.

It is worth pointing out that the results of this study cannot be generalized. Moreover, the results do not reflect the total scientific output of Brazilian PGPNur in the period in question. 


\section{Conclusion}

The presence of MDGs as an object of study in the 477 doctoral theses from the PGPNur with scores of 5 (national excellence), 6 and 7 (international excellence) between 2010 and 2012 in Brazil is still relatively slight, in other words, 174 (36.48\%), despite their addressing the link between economic development and health conditions and quality of life for the population.

Fisher's exact test was used to test the association between the Program's score and whether or not the MDGs were covered, yielding $p$-value $=0.0059$, showing that the hypothesis was confirmed that there is a link between the distribution of theses produced in the PGPNur, according to scores and the relation with the MDGs present.

It was also confirmed that there was an association between the scores from these Programs and the distribution of the theses and whether or not they included the MDGs ( $p$-value 0.0347).

PGPNur are recommended to become closer to the MDGs, ensuring nursing responsibility in conducting studies capable of increasing knowledge and caring for concrete social demands and needs.

\section{Referências}

1. Instituto de Pesquisa Econômica Aplicada e Secretaria de Planejamento e Investimentos Estratégicos. Grupo Técnico para o acompanhamento dos ODM. Objetivos de Desenvolvimento do Milênio: Relatório Nacional de Acompanhamento. Brasília: Ipea; 2014. [acesso 25 nov 2014]. Disponível em: http://www.pnud.org.br/Docs/5_ RelatorioNacionalAcompanhamentoODM.pdf

2. Souza A Filho. O ideal de universidade e sua missão. In: Moll J, Sevegnani P, organizadores. Universidade e Mundo do Trabalho. Brasília-DF: INEP; 2001. p. 173-84. 3. Silva NA, Camillo SO. A educação em enfermagem à luz do paradigma da complexidade. Rev Esc Enferm USP. 2007;41(3):403-10.

4. Brito MB. O que é universidade? Flash UCG. 2012. [acesso 2 jul 2012]. Disponível em: http://www2.ucg. br/flash/artigos/OQueEUniversidade.htm

5. Marcovitch J. Estudos avançados na universidade. Estud Avançados. 2011;25(73):127-31.

6. Pinho JGT. Cozinhando a geometria de redes de pesquisa com apropriações em ciência: conexões apetitosas para candidatos a gourmet. Ciênc Cognição. $2005 ; 4(2): 42-54$.

7. Fawcett J, De Santo M. Contemporary Nursing Knowledge: analysis and evaluation of contemporary nursing knowledge: Nursing models and theories. $3^{\text {rd }}$ Philadelphia: Davis Company; 2013. 149 p.

8. Ministério da Saúde (BR). Departamento de Ciência e Tecnologia, Secretaria de Ciência, Tecnologia e Insumos Estratégicos. Pesquisa em Saúde no Brasil. Rev Saúde Pública. 2008;42(4):77-85.

9. Ministério da Saúde (BR). Secretaria de Ciência, Tecnologia e Insumos Estratégicos. Departamento de Ciência e Tecnologia. Agenda nacional de prioridades de pesquisa em saúde. $2^{a}$ ed. Brasília: Editora do Ministério da Saúde; 2008. 44 p.

10. Erdmann AL, Fernandes JD, Lunardi VL, Robazzi MLCC, Rodrigues RAP. O alcance da excelência por programas brasileiros de pós-graduação stricto sensu com doutorado em enfermagem. Texto Contexto Enferm. 2012;21(1):130-9.

11. Coordenação de Aperfeiçoamento de Pessoal de Nível Superior [Internet]. Brasília: CAPES; 2014. [acesso 20 set 2014]. Disponível em: http://www.capes.gov.br.

12. Victora $C G$, Barreto $M L$, Leal $M C$, Monteiro $C A$, Schmidt MI, Paim $\mathrm{J}$ et al. Health conditions and healthpolicy innovations in Brazil: the way forward. Lancet 2011; 377(9782):2042-53.

13. Oliveira DC, Ramos FRS, Barros ALBL, Nóbrega MML. Classificação das áreas de conhecimento do CNPq e o campo da Enfermagem: possibilidades e limites. Rev Bras Enferm. 2013;66(esp):60-5.

14. Barros ALBL, Nóbrega ML, Santos RS, Cesar Vaz MR, Scochi CGS, Lopes CT, et al. Protagonismo da enfermagem na pesquisa.. Anais do $66^{\circ}$ Congresso Brasileiro De Enfermagem, 2014. Belém do Pará: ABEN; 2014. (No prelo)

15. Engler MB, Austin JK, Grady P. The National Institute of Nursing Research Graduate Partnerships Program (NINRGPP): An opportunity for PhD students. Nurs Outlook. 2014;62(6):469-74.

16. Bruzos GAS, Kamimura HM, Rocha AS, Jorgetto TAC, Patricio KP. Meio ambiente em Enfermagem: suas interfaces e inserção no ensino de graduação. Saúde Soc. $2011 ; 20(2): 462-9$.

17. Souza CL, Andrade CS. Saúde, ambiente e territórios: uma discussão necessária na formação em saúde. Ciênc Saúde Coletiva. 2014;19(10):4113-22. 
18. Camponogara S, RamosFRS, Kirchhof ALC. Reflexivity, knowledge and ecological awareness: premises for responsible action in the hospital work environment. Rev. Latino-Am Enfermagem. 2009;17:103-6.

19. Hill NL, Yevchak A, Kolanowski AM, Penrod J, Milone Nuzzo PF, Sawyer AM, et al. What it takes: perspectives from developing nurse scientists. J Nurs Educ. $2014 ; 53(7): 403-9$. 